\title{
Book Chapter Review: Hate Speech and Nigeria's Struggle for Democratic Consolidation: A Conceptual Review
}

\author{
Modu Alhaji Bukar* \\ Department of Mass Communication, University of Maiduguri, \\ PMB 1069, Maiduguri, Borno State, Nigeria \\ Adamkolo Mohammed Ibrahim \\ Department of Mass Communication, University of Maiduguri, \\ PMB 1069, Maiduguri, Borno State, Nigeria
}

\begin{abstract}
Disinformation and hate speech or dislike are not new to Nigerian polity. However, since the internet revolution in recent decades, 2015 is seen as the year Nigeria "finally woke up to the threat of disinformation and the way internet technologies are secretly and subtly used to undermine democracy" (White \& Elliott, 2018, p.5). Since then, whenever national, state or local council elections approach, Nigeria experiences tense and difficult times chaos, crises, conflicts, media propaganda, hate comments and false information climax thereby exposing the heightened political horse-trading, war against systemic and widespread corruption, debilitating poverty, weak institutions, threats of secession, etc. that are already nibbling at the country's fragile peace and unity. Because of the revolution in information and communication technology (ICT) and the attendant 'relative' democratisation of access and participation, election times in Nigeria should ideally be the time for the free flow of genuine, verified political information and tolerance. However, like in many other African countries, it is during these times that Nigeria wrestles with the rise in ethnic politics, regionalism and smear campaign that often escalate to the extent of threatening the country's political framework. Using a critical review of extant literature, this chapter provides further understanding on the impacts and processes of fake news and hate speech in Nigeria especially during political activities.
\end{abstract}

Keywords: Disinformation, Fake news, Hate speech, Nigerian democratic process

DOI: $10.7176 / \mathrm{NMMC} / 87-01$

Publication date: January $31^{\text {st }} 2020$

\section{Introduction}

Considering the critical position of the media and communication in a democracy: as important as the media and communication are, so is the quality or genuineness of the message and information circulating in the democratic atmosphere, between the politicians and voters (Abdullahi, 2019; Ibrahim, Yar'Adua \& Maikaba, 2019). In essence, we can confidently say that if logically, a lack of media and communication cripples any representative democracy, a lack of verifiable political message and information can, correspondingly or otherwise, pollute the democratic dispensation thereby undermining its development and sustenance. Therefore, a representative democratic process that is replete with information disorder and hate speech is, arguably, a weakling democracy (Adetula, 2015; Ibrahim \& Pate, 2019).

To enhance the strengths of the democracy and filter the filths of disinformation and hate speech for a stronger and better democratic governance, information released into the environment must be verifiably sound. And, there cannot be better technology to curb the menace of misleading information and hate speech in the society than the media themselves, that are used to pollute the democratic process. Strict adherence to regulatory codes, ethical journalism practice and fact-checking are shown to be the effective panacea. However, adherence to media regulatory codes and ethical journalism practice largely relate to conventional media - broadcast and print - while excluding the internet-based media which are largely unregulated, robustly popular and mostly used in the circulation of misleading contents and hate messages (Agbese, 2017; Ball, 2017). Therefore, the need for comprehensive techniques and tools of fact-checking cannot be over-emphasised.

The chapter which was authored by Prof. Umaru A. Pate and Malam Adamkolo Mohammed Ibrahim, MSc is titled Fake News, Hate Speech and Nigeria's Struggle for Democratic Consolidation: A Conceptual Review. It was published in a Book: Handbook of Research on Politics in the Computer Age edited by Prof. Ashu MG Solo, Maverick Technologies America, Inc., USA. The reputable publishing firm based at Hershey, in the USA state of Pennsylvania, IGI Global is the publisher. The 23-long chapter (pages 89-112) is the sixth chapter in the 436-page long book. The chapter is provided with a permanent digital placeholder or digital object identifier, DOI: 10.4018/978-1-7998-0377-5.ch006 with a printed book international standard serial number: ISSN: 2475-6814 and an electronic one: eISSN: 2475-6830. The front cover image is quite attractive and suggestive of the title or theme of the book: a computer superimposed against a background full of images suggesting political communication. 


\section{The Chapter Review}

To start with, the Handbook of Research on Politics in the Computer Age is a pivotal reference source that serves to increase the understanding of methods for politics in the computer age, the effectiveness of these methods, and tools for analyzing these methods. The book includes research chapters on different aspects of politics with information technology, engineering, computer science, or math, from 27 researchers at 20 universities and research organizations in Belgium, Brazil, Cape Verde, Egypt, Finland, France, Hungary, Italy, Mexico, Nigeria, Norway, Portugal and the United States of America. Highlighting topics such as online campaigning and fake news, the prospective audience includes, but is not limited to, researchers, political and public policy analysts, political scientists, engineers, computer scientists, political campaign managers and staff, politicians and their staff, political operatives, professors, students, and individuals working in the fields of politics, e-politics, e government, new media and communication studies, and Internet marketing (Solo, 2020).

The book chapter titled, Fake News, Hate Speech and Nigeria's Struggle for Democratic Consolidation: A Conceptual Review was authored by Professor Umaru A. Pate (Dean, School of Postgraduate Studies, Bayero University, Kano, Nigeria) and Adamkolo Mohammed Ibrahim (Lecturer, Department of Mass Communication, University of Maiduguri, Nigeria and PhD research candidate, Department of Mass Communication, Bayero University, Kano). The chapter is the sixth in an edited book titled, Handbook of Research on Politics in the Computer Age. The book was edited by Ashu M. G. Solo of Maverick Technologies America Incorporated, USA.

The chapter attempts to offer a new view into the definitions of the concept of fake news. The chapter also provided understanding about the impacts of fake news and hate speech in Nigerian democratic terrain, while offering some recommendations for curbing the negative effects of fake news and hate speech to preserve the country's hard-earned democratic values and processes and national unity.

The chapter consists of five major sections: background, in which fake news and hate speech definitions are analysed; literature review, which provides information about existing research in this area, i.e., on fake news and hate speech; solution and recommendations, which suggests future research directions; and conclusion and implications, which provides the concluding remarks of the chapter.

In the first section, the authors provide an in-depth analysis of the terms fake news and hate speech, establishing a conceptual link between the two terms, especially in the context of political communication regarding misinformation and inciteful media content. The authors further explain that for one to understand the fake news and hate speech in Nigerian polity, he or she must understand the ethno-religious conflicts, violent political culture and propaganda that can be so pervasive and widespread across or within states and/or regions. Most importantly, most ethno-religious conflicts have political undertones (Ibrahim, Gujbawu \& Abba-Aji, 2019).

Therefore, the outcome of the convergence of the aforementioned three 'undesirable elements' namely, ethnoreligious conflicts, violent political culture and propaganda is a compound terminology - fake news and hate speech - that is capable of disseminating disinformation virally and inciting wide-scale violence that often lead to deaths, displacement of people, destruction of property and robbing the society of the peace and harmony necessary for informed democratic participation by the citizenry (Allcott \& Gentzkow, 2017; Ibrahim et al., 2019).

In the second section of the chapter, the authors reviewed extant literature with a view to provide the reader a critical updated information about the research studies that have been done in this particular area of research; this is to situate their research work in the framework of existing research in fake news and hate speech both locally in Nigeria and globally. Prof Pate and Mr. Adamkolo Mohammed Ibrahim split the second section of the chapter into the following headings: 'Fake News and Social Media in Nigeria', 'The Impacts of Fake News on Nigerian Democratic System' and 'Conceptual Definition of Fake News' in which the scholars define fake news as 'false, often sensational, information disseminated under the guise of news reporting". To help towards scientific definitions of fake news, the authors designed a conceptual framework that was derived from extant literature review and proposed that it be adopted based on a quantitative approach. The conceptual framework focuses on providing an understanding on fake news based on the type of the sources of fake information and the degree of the likely influences of fake news on the nation's democratic process.

One of the two critical concepts that the authors wrote on is 'hate speech'. The scholars enumerate some factors that associate with hate speech including insulting others because of their religion, abusing others because of their ethnic or linguistic affiliations, expressing contempt against others because of their places of origin, disparaging or intimidating women or girls because of their gender and acts capable of leading to gender-based violence. Furthermore, as Prof Pate and Mr. Adamkolo noted, hate speech also encompasses condoning discriminatory assertions or statements against a group or groups of people, denigrating or ridiculing traditional or cultural institutions of others and deliberately spreading falsehood or rumours that are demeaning, demonizing, maligning or ostracizing others based on religion, ethnicity, gender or place of origin for the accident of one form of disability or the other. The scholars went further to stress that fake news and hate speech can create chaos capable of disrupting the peace in the society thereby undermining Nigeria's democratic process. An assertion several previous research works has agreed with (Agbese, 2017; Ansip, 2017; Siapera, 2018).

In the third section of the chapter, the authors highlight some critical means of identifying fake information 
in order to restrain the spread of fake news in the society, especially in Nigerian context. Among the factors they enumerate are: (i) to check and verify sources of information: that is, to encourage people and stations to fall back on most trusted news brands they could rely on for their news; (ii) to look at multiple sources: that is, to use online information verification tools; (iii) to think before broadcasting/publishing a story; and (iv) the necessity for media literacy among Nigerians, which can increase the standard of education and media literacy particularly for young people regarding what is genuine and verifiable information and what is fake. The authors further recommend that funding, ethics, partnership, credibility, media skills, regulation, collaboration, media literacy, professionalism, gatekeeping and self-censorship and detection are important steps toward fighting the menace of fake news and hate speech in the society.

In the fourth section of the chapter, the authors suggest some directions for further research. According to them, future research should focus on providing scientifically acceptable and locally standardized definitions of fake news and hate speech given the pervasiveness of the problems (especially in recent years) in the country as the nation could be enmeshed in the 'dark webs' of the internet and social media if fake news and hate speech prevail over our democratic values.

In the final section of their work, the authors conclude that, if fake news and hate speech are a weapon of 'mass democratic destruction', then it would not be out of place to declare that Nigeria and its democratic process are already 'under attack'. The authors also highlight some critical scenarios that are likely to occur (as mentioned earlier) during democratic exercises such as elections, with implications of fake news and hate speech on Nigeria's democratic process as articulated by many communication scholars.

On a general note, this chapter offers scholars, journalists and practitioners in communication and journalism studies and teaching distinct concepts of fake news and hate speech and their dynamic impacts in the Nigerian democratic process. The chapter leaves the reader with useful observations and ideas on how to restrain the spread of fake news in the society, especially in Nigerian context. I have immensely enjoyed reading and expanding my understanding of fake news and hate speech in Nigerian context through this chapter and recommend it for everybody to read and digest it, especially journalists, media workers, students of mass communication and journalism, politicians and scholars. A free e-copy of this book chapter is obtainable at this link: https://www.academia.edu/40439878/Fake_News_Hate_Speech_and_Nigerias_Struggle_for_Democratic_Conso lidation_A_Conceptual_Review

While readers who are interested in purchasing the whole book should follow this link: https://www.igiglobal.com/book/handbook-research-politics-computer-age/228093

\section{References}

Abdullahi, B. (2017 March 13). Democracy and the challenge of fake news. TheCable. Retrieved January 25, 2019 from https://www.thecable.ng/democracy-challenge-fake-news

Adetula, V. A. O. (2015). Godfathers, money politics, and electoral violence in Nigeria: Focus on 2015 elections. A paper presented at the two-day 'National Conference on the 2015 General Elections in Nigeria: The Real Issues' held at the Electoral Institute Complex, Abuja, July 27-28.

Agbese, D. (2017 December 31). The dangers of fake news. Daily Trust. Retrieved January 25, 2019 from https://www.dailytrust.com.ng/the-dangers-of-fake-news.html

Allcott, H. \& Gentzkow, M. (2017). Social media and fake news in the 2016 election. Journal of Economic Perspectives, 31(2), 211-236. Also available in National Bureau of Economic Research Working Paper 23089. Retrieved from http://www.nber.org/papers/w23089

Ansip, A. (2017). Hate speech, populism and fake news on social media - towards an EU response. Retrieved from http:/ec.europa.eu/commission/commissioners/2014-2019/ansip/announcements/stament-vicepresident-ansip-european-parliament-strasbourg-plenary-debate-hate-speech-populism_en

Ball, J. (2017). Post-truth: How bullshit conquered the world. London: Biteback Publishing.

Ibrahim, A. M., Gujbawu, M. \& Abba-Aji, N. (2019). Enough is enough of this conflict. Peace is all we want: Advocacy for mediatisation and digitisation of de-bokoharamisation campaign. In J. A. Opara (Ed.), Outlook on human capacity building and development: A handbook of research in honour of Professor Ibrahim Njodi (pp. 11-130). Maiduguri: University of Maiduguri Press.

Ibrahim, A. M. \& Pate, U. A. (2019). In a democratised media context what a hoax can do, a misinformation can do even worse: Influences of fake news on democratic processes in Nigeria. New Media and Mass Communication, 79, 10-17.

Ibrahim, A. M., Yar'Adua, S. M. \& Maikaba, B. (2019). More media, less democratisation of public access and participation: A conceptual review on influence of deregulation and commercialisation on public broadcasting in Nigeria. International Journal of Telecommunications and Information Technology, 3(1), 32-46.

Siapera, E. (2018). Understanding new media. London: Sage. 